\title{
EPIDEMIOLOGICAL STUDY OF OROFACIAL CLEFTS AMONG POPULATION OF EASTERN SLOVAKIA DURING THE PERIOD 1996-2013
}

\author{
Diana Pacáková1, Marianna Zábavníková2, Mária Miklošová3, Diana Kúkel'ová1, Róbert Dankovčík ${ }^{4,5}$ \\ ${ }^{1}$ Institute of Biology and Ecology, P. J. Šafárik University in Košice, Košice, Slovak Republic \\ ${ }^{2}$ Department of Plastic, Reconstructive and Aesthetic Surgery, L. Pasteur University Hospital, Košice, Slovak Republic \\ ${ }^{3}$ Department of Anatomy, Faculty of Medicine and Dentistry, Palacký University, Olomouc, Czech Republic \\ ${ }^{4}$ 2nd Department of Obstetrics and Gynaecology, P. J. Šafárik University and L. Pasteur University Hospital, Košice, Slovak Republic \\ ${ }^{5}$ Centre for Prenatal Diagnosis, Košice, Slovak Republic
}

\section{SUMMARY}

Background and Aim: Over the past 18 years, according to data from the Clinic of Plastic and Reconstructive Surgery, L. Pasteur University Hospital, there have been 493 cases of orofacial clefts $(\mathrm{OC})$ reported in the area of Eastern Slovakia. The aim of this study was to map the occurrence of orofacial clefts reported in the area of Eastern Slovakia during the years 1996-2013. Also, we compared the occurrence of different types of clefts between the groups in relation to gender and ethnicity.

Methods and Results: The statistical analysis shows relationship between variables of location and gender and gender differences in the occurrence of various types of clefts. Moreover, in comparison with another study which analyzed the years 1985-2000 (1.29/10 live births), there was an increase in the incidence $\left(1.42 / 10^{3}\right.$ live births) of OC in Eastern Slovakia.

Conclusion: Our findings seem contradictive to similar studies which discuss ethnic differences in relation to OC. We recognize the relatively high occurrence of OC in Eastern Slovakia, and we link this phenomenon to several extrinsic factors, in particular socioeconomic status and embryotoxic factors.

Key words: cleft lip and/or palate, incidence, ethnic group, Eastern Slovakia regions

Address for correspondence: M. Miklošová, Department of Anatomy, Faculty of Medicine and Dentistry, Palacký University, Hněvotínská 3, 77515 Olomouc, Czech Republic. E-mail: maria.miklosova@upol.cz

http://dx.doi.org/10.21101/cejph.a4131

\section{INTRODUCTION}

The most common orofacial anomaly, a cleft lip (CL) and/or cleft palate (CLP/CP) (1), occurs in approximately one of 600-660 births in Slovakia, which is slightly higher than the European average ( 1 out of 700-750 births). According to the epidemiological statistics, the frequency of occurrence of the cleft lip and/or palate in Slovakia ranks 9th among all congenital anomalies (2). Anomalies occurrence shows substantial variation among ethnic groups (3), gender and geographical areas (4). Cleft lip and/or palate represent a multifactorial malformation including genetic disorders, and multiple nutritional and toxicological factors. Failure in palatogenesis causes a cleft lip and/or palate. The palate is formed relatively late in organogenesis: at 8-12 intrauterine weeks in humans (3). Experimental study on the normal palate closure and experimental analysis of mechanisms using teratogens and genetic differences have contributed greatly towards understanding of palatogenesis process and clefting although the whole mechanism of cleft is not yet fully explored. CP and CL are not homogeneous in population. There are crucial variables that provide basis for the establishment of subgroups (5). To determine the incidence of CP and CL, a classification of orofacial clefts is needed.
The aim of this study was to map the occurrence of orofacial clefts reported in the area of Eastern Slovakia during the years 1996-2013. Also, we compared the occurrence of different types of clefts between the groups in relation to gender and ethnicity.

\section{Classification of Orofacial Clefts}

There are several classifications of orofacial clefts available. Some scholars consider the alveolar ridge as a significant landmark in the division of oral clefts. For instance, Kernahan and Stark's classification puts an emphasis on incisive foramen which marks the boundary between the primary palate (anterior to the incisive foramen) and the secondary palate (posterior to the incisive foramen). Clefting can therefore occur in the primary palate, the secondary palate or in both. Thus it may be complete, incomplete, unilateral or bilateral (4). In Kernahan and Stark's classification, deformity is linked to the letter Y. Also, this classification divides clefts into three groups: clefts of primary palate, clefts of secondary palate and clefts of both palates (primary and secondary) (6).

Different clefts represent different epidemiology and rates due to social and demographic variables (7). We use the classifica- 
tion of orofacial clefts (OC) by Kernahan and Stark to determine the incidence of cleft lip and palate in the Eastern Slovakia (ES) population.

\section{MATERIALS AND METHODS}

Over the last 18 years, 493 new cases of cleft lip and/or palate have been reported by the Department of Plastic, Reconstructive and Aesthetic Surgery, L. Pasteur University Hospital, the catchment area of ES. Out of 493 children (gender ratio 1.38:1), 286 (58.01\%) were male, 207 (41.99\%) were female; 54.97\% belonged to a non-Roma population, and $45.03 \%$ to a Roma population. The data for statistical analysis gathered from the medical records were divided into four groups based on the types of clefts by Kernahan and Stark - CLP, CL, CP, associated malformations (AM), including variations between gender and ethnic group. According to location, types of clefts were left-sided, right-sided and bilateral clefts. The data from the CLP, CL, CP groups included individuals whose clefts were nonsyndromic. The AM group included individuals with Pierre Robin syndrome. We applied the unpaired T-test for statistical analysis of data with statistical significance $p<0.05$, to analyze differences in types of clefts between the two groups in relation to gender and ethnicity.

\section{RESULTS}

From 1996 to 2013, 493 diagnosis and treatment of cleft lip and/or palate had been performed in ES at the aforementioned
Department of Plastic, Reconstructive and Aesthetic Surgery, L. Pasteur University Hospital (Table 1, Fig. 1). Total incidence of orofacial clefts was $1.42 / 10^{3}$ live births (LB). $45.23 \%$ of 493 cases affected the primary and secondary palate, $27.79 \%$ were cleft palate, $24.34 \%$ cleft lip, and $2.64 \%$ were associated malformations with variation between gender and ethnic group. Out of 120 diagnosis of CL, $65.83 \%$ were on left side, $30 \%$ right-sided and $4.17 \%$ were bilateral. There were $47.53 \%$ left-sided CLP cases, $19.73 \%$ right-sided CLP and $32.74 \%$ bilateral CLP of total incidence of CLP $(n=223)$ in the examined patients. Comparing between gender (females vs. males), out of 128 cases of CL and CLP in $57.81 \%$ of females left side was affected, in $24.22 \%$ right side and $17.97 \%$ were bilateral. Out of 215 cases of CL and CLP in males $51.63 \%$ were left-sided, $22.79 \%$ were right-sided and

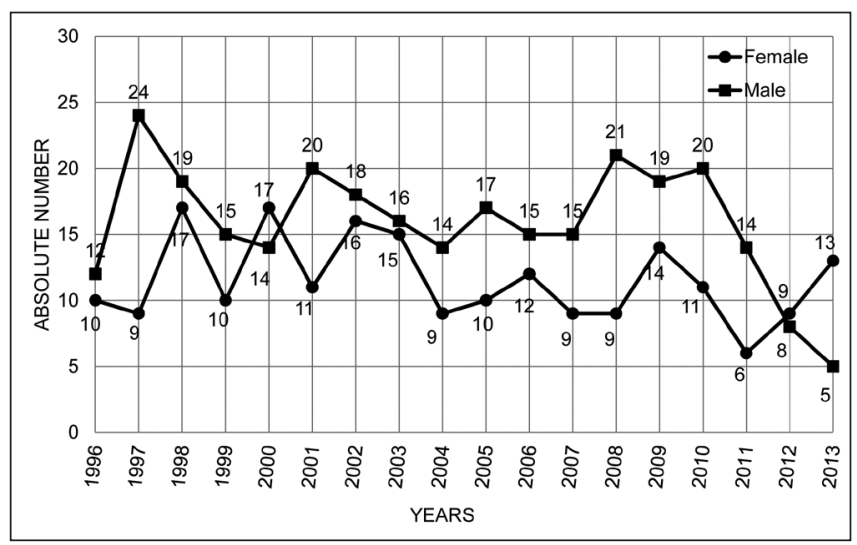

Fig. 1. Absolute number of orofacial clefts/gender in the period 1996-2013.

Table 1. Number of orofacial clefts in the period 1996-2013, according to cleft types

\begin{tabular}{|c|c|c|c|c|c|}
\hline \multirow{2}{*}{ Year } & \multicolumn{4}{|c|}{ Cleft types } & \multirow{2}{*}{ Total } \\
\hline & $\mathrm{CL}$ & CLP & $\mathrm{CP}$ & AM & \\
\hline 1996 & $5(22.73 \%)$ & $12(54.54 \%)$ & $5(22.73 \%)$ & $0(0 \%)$ & 22 \\
\hline 1997 & $10(30.30 \%)$ & $14(42.43 \%)$ & $9(27.27 \%)$ & $0(0 \%)$ & 33 \\
\hline 1998 & $7(19.44 \%)$ & $18(50 \%)$ & $10(27.78 \%)$ & $1(2.78 \%)$ & 36 \\
\hline 1999 & $4(16 \%)$ & $14(56 \%)$ & $7(28 \%)$ & $0(0 \%)$ & 25 \\
\hline 2000 & $7(22.58 \%)$ & $12(38.71 \%)$ & $11(35.48 \%)$ & $1(3.23 \%)$ & 31 \\
\hline 2001 & $6(19.35 \%)$ & $19(61.30 \%)$ & $6(19.35 \%)$ & $0(0 \%)$ & 31 \\
\hline 2002 & $8(23.53 \%)$ & $11(32.35 \%)$ & $14(41.18 \%)$ & $1(2.94 \%)$ & 34 \\
\hline 2003 & $11(35.48 \%)$ & $12(38.71 \%)$ & $6(19.35 \%)$ & $2(6.46 \%)$ & 31 \\
\hline 2004 & $5(21.74 \%)$ & $15(65.22 \%)$ & $2(8.69 \%)$ & $1(4.35 \%)$ & 23 \\
\hline 2005 & $7(25.92 \%)$ & $10(37.04 \%)$ & $10(37.04 \%)$ & $0(0 \%)$ & 27 \\
\hline 2006 & $8(29.63 \%)$ & $6(22.22 \%)$ & $11(40.74 \%)$ & $2(7.41 \%)$ & 27 \\
\hline 2007 & $5(20.83 \%)$ & $13(54.17 \%)$ & $4(16.67 \%)$ & $2(8.33 \%)$ & 24 \\
\hline 2008 & $4(13.34 \%)$ & $13(43.33 \%)$ & $13(43.33 \%)$ & $0(0 \%)$ & 30 \\
\hline 2009 & $12(36.37 \%)$ & $11(33.33 \%)$ & $10(30.30 \%)$ & $0(0 \%)$ & 33 \\
\hline 2010 & $8(25.81 \%)$ & $18(58.06 \%)$ & $5(16.13 \%)$ & $0(0 \%)$ & 31 \\
\hline 2011 & $3(15 \%)$ & $10(50 \%)$ & $6(30 \%)$ & $1(5 \%)$ & 20 \\
\hline 2012 & $4(23.53 \%)$ & $9(52.94 \%)$ & $4(23.53 \%)$ & $0(0 \%)$ & 17 \\
\hline 2013 & $6(33.33 \%)$ & $6(33.33 \%)$ & $4(22.23 \%)$ & $2(11.11 \%)$ & 18 \\
\hline Total & $120(24.34 \%)$ & $223(45.23 \%)$ & 137 (27.79\%) & $13(2.64 \%)$ & 493 \\
\hline
\end{tabular}

CL - cleft lip, CLP - cleft lip and palate, CP - cleft palate, AM - associated malformation 
$25.58 \%$ were bilateral. The following part of the article is devoted to the detailed results of the statistical data processing.

\section{Cleft Lip and Palate}

From 220 cases of patients with a cleft lip and palate, in 33.18\% of non-Roma males and $30.04 \%$ of Roma males the primary and secondary palate was affected (Fig. 2). Roma females were less affected (17.04\%) compared with Roma males and non-Roma males; non-Roma females represented $19.74 \%$ of cases. Statistical significance was found in the three compared groups: non-Roma females vs. non-Roma males $(\mathrm{p}<0.0106)$; Roma females vs. Roma males $(p<0.0184)$; females vs. males $(p<0.0002)$. This significance represents a very close correlation between females and males in the examined patients (Table 2).

\section{Cleft Lip}

The incidence of cleft lip ranged from $21.67 \%$ for non-Roma females to $30 \%$ for non-Roma males with the total incidence of CL $(n=120)$ in the examined patients. The incidence of cleft lip was lower among Roma females compared with non-Roma females, and it represented $16.66 \%$; for Roma males the rate was $31.67 \%$ of total incidence of cleft lip $(n=120)$ in the examined patients (Fig. 3). Statistical significance was found in the two compared groups, including Roma males and Roma females $(\mathrm{p}<0.0104)$, the significance was also found between females and males $(p<0.0089)$ (Table 2$)$.

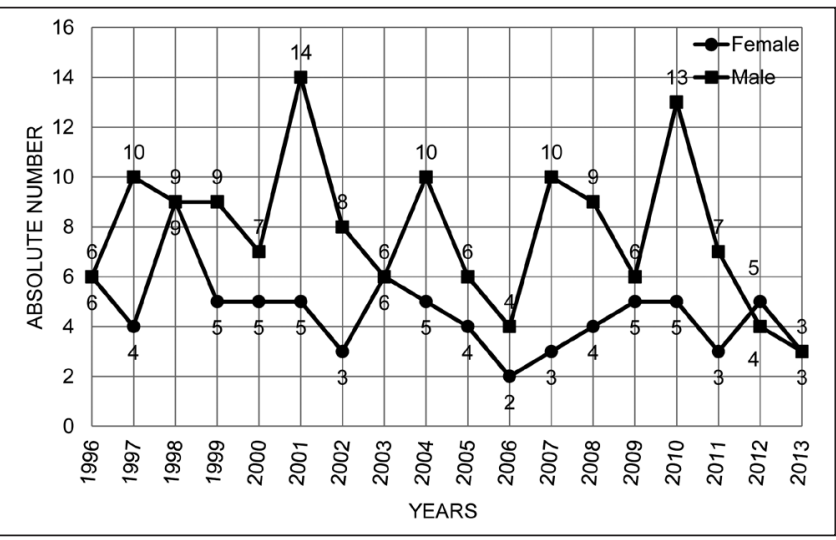

Fig. 2. Absolute number of cleft lip and palate for males (square) and females (circle) in the period 1996-2013.

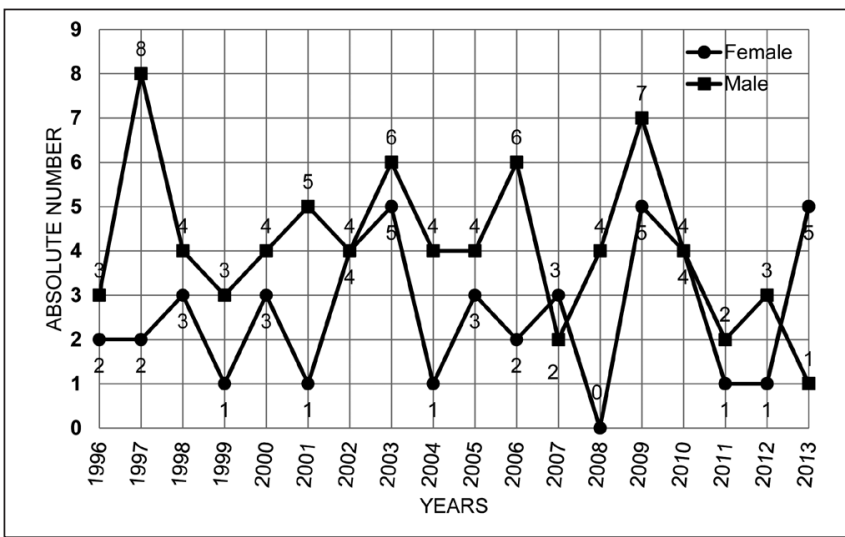

Fig. 3. Absolute number of cleft lip for males (square) and females (circle) in the period 1996-2013.

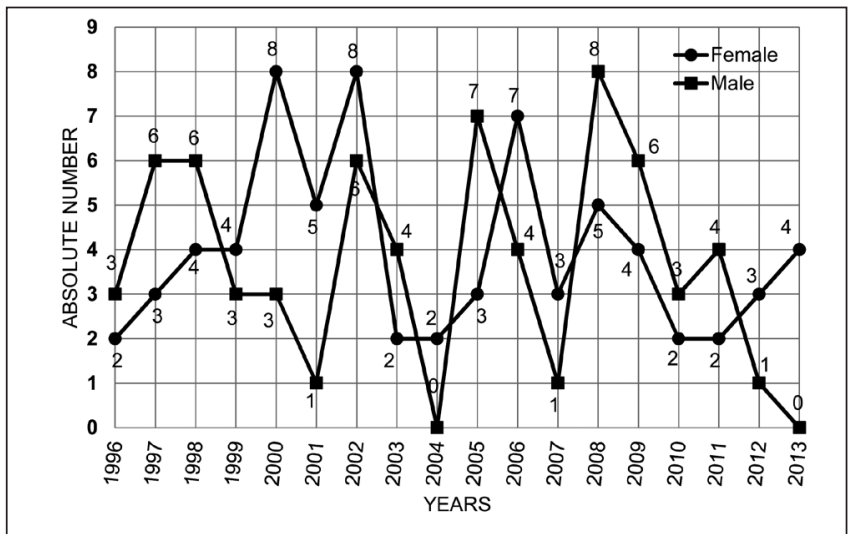

Fig. 4. Absolute number of cleft palate for males (square) and females (circle) in the period 1996-2013.

\section{Cleft Palate}

The highest incidence of cleft palate $(n=137,30.66 \%)$ occurred among non-Roma females and also males. The total incidence of cleft palate was 137 cases, $21.16 \%$ of cleft palate were observed in Roma females and $17.52 \%$ in Roma males (Fig. 4). There was no significant difference between the compared groups in this type of cleft (Table 2).

\section{Associated Malformations}

Out of 13 cases, the highest incidence of AM was observed in non-Roma females (38.46\%). Also, $15.38 \%$ of non-Roma males

Table 2. Statistical significance of each type of cleft/group in the period 1996-2013 (p values)

\begin{tabular}{|l|c|c|c|c|}
\hline \multirow{2}{*}{} & \multicolumn{5}{|c|}{ Cleft types } \\
\cline { 2 - 5 } & CLP & CL & CP & AM \\
\hline Group1 & $\mathrm{ns}$ & $\mathrm{ns}$ & $\mathrm{ns}$ & $\mathrm{ns}$ \\
\hline Group 2 & $\mathrm{ns}$ & $\mathrm{ns}$ & $\mathrm{ns}$ & $\mathrm{ns}$ \\
\hline Group 3 & $0.0106^{*}$ & $\mathrm{~ns}$ & $\mathrm{~ns}$ & $\mathrm{~ns}$ \\
\hline Group 4 & $0.0184^{*}$ & $0.0104^{*}$ & $\mathrm{~ns}$ & $\mathrm{~ns}$ \\
\hline Group 5 & $0.0002^{* * *}$ & $0.0089^{* *}$ & $\mathrm{~ns}$ & $\mathrm{~ns}$ \\
\hline
\end{tabular}

${ }^{*} p$ value $<0.05,{ }^{* *} p$ value $<0.01,{ }^{* * *} p$ value $<0.001$, ns - not significant

Group 1 represents Roma male compared with non-Roma male. Group 2 represents Roma female compared with non-Roma female. Group 3 represents non-Roma female compared with non-Roma male. Group 4 represents Roma female compared with Roma male. Group 5 represents female compared with male.

$\mathrm{CLP}$ - cleft lip and palate, CL - cleft lip, CP - cleft palate, AM - associated malformation 
were affected with AM, the proportion of Roma females and Roma males were the same (23.08\%). There was no statistical significance in this type of cleft between the compared groups (Table 2).

\section{DISCUSSION}

$\mathrm{OC}$ are the most common congenital malformations which occur frequently all over the world $(1,8)$. In Europe, a higher incidence of OC was detected in Poland, Sweden and the Czech Republic (2.0/10 live births). Finland, for example, is a European country with the lowest incidence of clefts $\left(0.79 / 10^{3}\right.$ live births); nevertheless, the incidence in this country is increasing. The Slovak Republic is considered to be a country with a relatively high incidence $\left(1.60 / 10^{3}\right.$ live births) of clefts anomalies $(8,9)$.

The various differences in incidence of OC have been greatly discussed amongst scholars. The occurrence of OC varies in geographical distribution, race and ethnic differences. Generally, a higher risk of clefts has been found in the white race population than in the black population, although a high range of differences among countries exist $(8,10)$. The results of this study show no significance between chosen ethnic groups (non-Roma vs. Roma). Although, there is a significance between females and males in following types of clefts - CLP, CL (non-Roma females vs. non-Roma males, Roma females vs. Roma males, females vs. males in CLP; and Roma females vs. Roma males, females vs. males in CL). These results support findings of many researchers who discuss gender differences in health status (11-14). Gender distribution of particular OC showed a male predominance in the CL (61.67\%) and CLP (63.23\%) types of clefts, and female predominance in $\mathrm{CP}(51.82 \%)$ and $\mathrm{AM}(61.54 \%)$ types of clefts, which is in accordance with the data of the epidemiological study from Croatia and related studies $(8,10,15,16)$. Due to the predominance of left-sided OC as documented in similar studies ( 7 , $10,15,17)$, our results confirm left-sided OC as the most common ( $65.83 \%$ for CL and $47.53 \%$ for CLP) in the examined patients. Mossey et al. suggest the importance of genetic susceptibility in the predominance of a left-sided clefting and the male excess of a cleft lip and palate (17). Others, for instance, analyze sexual dimorphism in the male predominance of CLP and CL, and female predominance of $\mathrm{CP}$ and their resistance to the development of CLP and CL (8).

Drawing on our data findings, the total incidence of $1.42 / 10^{3}$ live births in ES in 1996-2013 (the overall number of live-born children in ES per 18 years was 347,715) marked an increase of prevalence compared to the previous study, analysing the data between 1985-2000, where the total incidence of OC in ES was defined as $1.29 / 10^{3}$ LB (8). According to the study from 19852000 , the lowest incidence was documented in the eastern part of Slovakia. This fact, however, is not consistent with our results.

More research needs to be done to examine the link between ethnic affiliation and socioeconomic status in regard to the occurrence of OC. In this respect, Roma are well-known for their low socioeconomic status and this may reduce the level of health among Roma (18).

Although there is some evidence supporting a positive relationship between ethnic groups and socioeconomic status in the literature (19-22), our study has found little or no significance between the ethnic groups. However, some associations between socioeconomic status and health in non-Roma populations have been found in many studies (23-25). Genetic, biological, medical, and anthropological analyses of Roma health status focus greatly on infectious diseases or hereditary defects $(18,26-28)$. However, due to the socioeconomic conditions, these factors seem to be potential risk factors of incidence of OC in ES.

To analyze the potential risk factors related to the occurrence of OC, the Department of Plastic, Reconstructive and Aesthetic Surgery, L. Pasteur University Hospital conducted the study. The questionnaires were used to investigate possible risk causes. The results showed that $45 \%$ of pregnant women overcame upper respiratory infections and flu, $28 \%$ of pregnant women used drugs during pregnancy, in $23.4 \%$ of cases the cleft occurred in the family and in $9 \%$ of cases the other congenital defects occurred in the family (29). Environmental and genetic factors play an important role in aethiopatogenesis of OC. Finding the embryotoxic factors, such as maternal smoking, infectious diseases, drugs, professional exposure to chemicals during pregnancy and lifestyle, allow prevention of OC during pregnancy, mainly during the critical period of prenatal development (27th-60th embryonic day) (30).

\section{CONCLUSION}

The occurrence of various types of clefts was studied in a population of ES in relation to gender and ethnic group. We recorded an increased incidence of OC in Eastern Slovakia (1.42/103 LB) from 1996 to 2013, and also gender differences in prevalence of OC, which show a male predominance in the CL (61.67\%) and CLP (63.23\%) types of clefts, and female predominance in the CP (51.82\%) and AM (61.54\%) types of clefts. Our study does not support findings of authors who discuss ethnic differences in the incidence of OC. Little or no significance has been found between selected ethnic groups (non-Roma vs. Roma). In case of the low socioeconomic status in ES and its relation to the potential embryotoxic factors affecting women during pregnancy, we acknowledge these factors as potential risk factors of incidence of OC.

\section{Acknowledgement}

We thank to the Department of Plastic, Reconstructive and Aesthetic Surgery, L. Pasteur University Hospital for providing the hospital episode statistics data used in this study.

\section{Conflict of Interests}

None declared

\section{REFERENCES}

1. Mosahebi A, Kangesu L. Cleft lip and palate. Surgery (Oxford). 2006;24(1):33-7.

2. Kokavec R, Hedera J, Fedeles J, Janovic J, Kratka E, Klimova I. New trends in the complex treatment in the Cleft Centre in Bratislava. Bratisl Lek Listy. 2001;102(6):290-3.

3. Dudas M, Li WY, Kim J, Yang A, Kaartinen V. Palatal fusion - where do the midline cells go? A review on cleft palate, a major human birth defect. Acta Histochem. 2007;109(1):1-14.

4. Thornton JB, Nimer S, Howard PS. The incidence, classification, etiology, and embryology of oral clefts. Semin Orthod. 1996 Sep;2(3):162-8. 
5. Spriestersbach DC, Dickson DR, Fraser FC, Horowitz SL, McWilliams BJ, Paradise JL, et al. Clinical research in cleft lip and cleft palate: the state of the art. Cleft Palate J. 1973 Apr;10:113-65.

6. Shah SN, Khalid M, Khan MS. A review of classification systems for cleftlip and palate patients II. Embryological classifications. JKCD. 2012;2(2):86-91.

7. Yáñez-Vico RM, Iglesias-Linares A, Gómez-Mendo I, Torres-Lagares D, González-Moles MÁ, Gutierrez-Pérez JL, et al. A descriptive epidemiologic study of cleft lip and palate in Spain. Oral Surg Oral Med Oral Pathol Oral Radiol. 2012 Nov;114(5 Suppl):S1-4.

8. Macháčová E, Bánsky R, Špaleková M, Guzanin S, Sabovčík R, Slobodník L. Incidence of orofacial clefts in the Slovak Republic. Cent Eur J Public Health. 2006 Sep;14(3):122-5.

9. Peterka M, Peterková R, Likovský Z, Tvrdek M, Fára M. Incidence of orofacial clefts in Bohemia (Czech Republic) in 1964-1992. Acta Chir Plast. 1995;37(4):122-6

10. Magdalenić-Mestrović M, Bagatin M. An epidemiological study of orofacial clefts in Croatia 1988-1998. J Craniomaxillofac Surg. 2005 Apr;33(2):85-90.

11. Mani M, Carlsson M, Marcusson A. Quality of life varies with gender and age among adults treated for unilateral cleft lip and palate. Cleft Palate Craniofac J. 2010 Sep;47(5):491-8.

12. Annandale E, Hunt K. Gender inequalities in health. Buckingham: Open University Press; 2000.

13. Macintyre S, Hunt K, Sweeting H. Gender differences in health: are things really as simple as they seem? Soc Sci Med. 1996 Feb;42(4):617-24.

14. Oksuzyan A, Juel K, Vaupel JW, Christensen K. Men: good health and high mortality. Sex differences in health and aging. Aging Clin Exp Res. 2008 Apr;20(2):91-102.

15. Shapira Y, Lubit E, Kuftinec MM, Borell G. The distribution of clefts of the primary and secondary palates by sex, type, and location. Angle Orthod. 1999 Dec;69(6):523-8.

16. Fedeles J Jr, Ziak P, Krizko M, Payer J Jr, Bohac M, Palencar D, et al. Prevalence of cleft lip and palate in western Slovakia in the years 20012007. Bratisl Lek Listy. 2012;113(2):117-9.

17. Mossey PA, Little J, Munger RG, Dixon MJ, Shaw WC. Cleft lip and palate. Lancet. 2009 Nov 21;374(9703):1773-85.

18. Kolarcik P, Geckova AM, Orosova O, van Dijk JP, Reijneveld SA. To what extent does socioeconomic status explain differences in health between Roma and non-Roma adolescents in Slovakia? Soc Sci Med. 2009 Apr;68(7):1279-84.
19. Kington RS, Smith JP. Socioeconomic status and racial and ethnic differences in functional status associated with chronic diseases. Am J Public Health. 1997 May;87(5):805-10.

20. Ward E, Jemal A, Cokkinides V, Singh GK, Cardinez C, Ghafoor A, et al. Cancer disparities by race/ethnicity and socioeconomic status. CA Cancer J Clin. 2004 Mar-Apr;54(2):78-93.

21. Kraus JF, Borhani NO, Franti CE. Socioeconomic status, ethnicity, and risk of coronary heart disease. Am J Epidemiol. 1980 Apr;111(4):407-14.

22. Sedláková D. Low socioeconomic status and unhealthy lifestyle lead to high morbidity in young Roma of East Slovakia. Cent Eur J Public Health. 2014 Mar;22 Suppl:S3-5.

23. Craig N. Exploring the generalisability of the association between income inequality and self-assessed health. Soc Sci Med. 2005 Jun;60(11):247788.

24. Dunn JR, Veenstra G, Ross N. Psychosocial and neo-material dimensions of SES and health revisited: predictors of self-rated health in a Canadian national survey. Soc Sci Med. 2006 Mar;62(6):1465-73.

25. Nazroo J, Jackson J, Karlsen S, Torres M. The Black diaspora and health inequalities in the US and England: does where you go and how you get there make a difference? Sociol Health Illn. 2007 Sep;29(6):811-30.

26. Puhó E, Métneki J, Czeizel AE. Maternal employment status and isolated orofacial clefts in Hungary. Cent Eur J Public Health. 2005 Sep;13(3):1448.

27. Koupilová I, Epstein H, Holcík J, Hajioff S, McKee M. Health needs of the Roma population in the Czech and Slovak Republics. Soc Sci Med. 2001 Nov;53(9):1191-204

28. Rambousková J, Dlouhý P, Krízová E, Procházka B, Hrncírová D, Andel M. Health behaviors, nutritional status, and anthropometric parameters of Roma and non-Roma mothers and their infants in the Czech Republic. J Nutr Educ Behav. 2009 Jan-Feb;41(1):58-64.

29. Zábavníková M. Possibility of surgical treatment of unilateral clefts defects of lip and palate [dissertation]. Košice: P. J. Safarik University 2005.

30. Peterka M, Peterková R, Tvrdek M, Kuderová J, Likovský Z. Significant differences in the incidence of orofacial clefts in fifty-two Czech districts between 1983 and 1997. Acta Chir Plast. 2000;42(4):124-9.

Received October 6, 2014 Accepted in revised form June 26, 2015 